\title{
IL-23 and IL-17 in ankylosing spondylitis
}

\author{
Daniel Wendling
}

Received: 19 August 2009/Accepted: 7 October 2009/Published online: 4 November 2009

(C) Springer-Verlag 2009

Sir,

We read with interest the study published by Wang et al. demonstrating the elevated levels of IL-23 and IL-17 in the serum of patients with active Ankylosing Spondylitis (AS) [1].

This illustrates the potential central role of the IL-23/IL17 axis in AS [2], and is concordant with other findings, such as IL-23 receptor polymorphisms in AS, as well as in Crohn's disease or in psoriasis [3], sharing the concept of spondyloarthropathy. Elevated IL-17 levels were found in the serum of AS patients [4], and increased numbers of Th 17 cells in the peripheral blood of patients with seronegative spondylarthritides (and not RA) were reported by Jandus [5], as well as increased frequencies of IL-17 positive CD4+ T cells in PBMC from patients with AS [6].

Moreover, for the first time, a higher expression of IL-23 p19 mRNA in PBMC of AS patients as well as enhanced production of IL-17 in the supernatants of PBMC cultured in the presence of recombinant IL-23 was found by Wang et al. [1]. Previous studies did not demonstrate elevated levels of p40 IL-23 in the serum of AS patients, compared with controls, whereas, in some of them, synovial fluid levels were higher than serum levels [7]. This gives the central role to p40 IL-23 in the pathophysiological axis, and a potential theraputic target in AS. Nevertheless, it has been demonstrated that targeting p40 IL-12/23 with a

\section{Wendling ( $₫)$}

Department of Rheumatology, University Teaching Hospital,

Boulevard Fleming, 25030 Besançon, France

e-mail: dwendling@chu-besancon.fr

D. Wendling

EA 3186, University of Franche-Comté,

Besançon, France monoclonal antibody (ustekinumab) may be effective in treating psoriatic arthritis [8], psoriasis, and Crohn's disease.

According to the results of Wang et al. [1], one may speculate that p19 IL-23 blockade may be even more efficacious, and may represent a new therapeutic pathway in AS.

Conflict of interest statement None.

\section{References}

1. Wang X, Lin Z, Wei Q et al (2009) Expression of IL-23 and IL-17 and effect of IL-23 on IL-17 production in ankylosing spondylitis. Rheumatol Int 29:1343-1347

2. Wendling D (2008) Interleukin 23: a key cytokine in chronic inflammatory disease. Joint Bone Spine 75:517-519

3. Karaderi T, Harvey D, Farrar C et al (2009) Association between the interleukin 23 receptor and ankylosing spondylitis is confirmed by a new UK case control study and meta-analysis of published series. Rheumatology (Oxford) 48:386-389

4. Wendling D, Cedoz JP, Racadot E, Dumoulin G (2007) Serum IL-17, BMP-7, and bone turnover markers in patients with ankylosing spondylitis. Joint Bone Spine. 74:304-305

5. Jandus C, Bioley G, Rivals JP et al (2008) Increased numbers of circulating polyfunctional Th17 memory cells in patients with seronegative spondylarthritides. Arthritis Rheum 58:2307-2317

6. Shen H, Goodall JC, Hill Gaston JS (2009) Frequency and phenotype of peripheral blood Th17 cells in ankylosing spondylitis and rheumatoid arthritis. Arthritis Rheum 60:1647-1656

7. Wendling D, Cedoz JP, Racadot E (2009) Serum and synovial fluid levels of p40 IL12/23 in spondyloarthropathy patients. Clin Rheumatol 28:187-190

8. Gottlieb A, Menter A, Mendelsohn A et al (2009) Ustekinumab, a human interleukin 12/23 monoclonal antibody, for psoriatic arthritis: randomised, double-blind, placebo-controlled, crossover trial. Lancet 373:633-640 